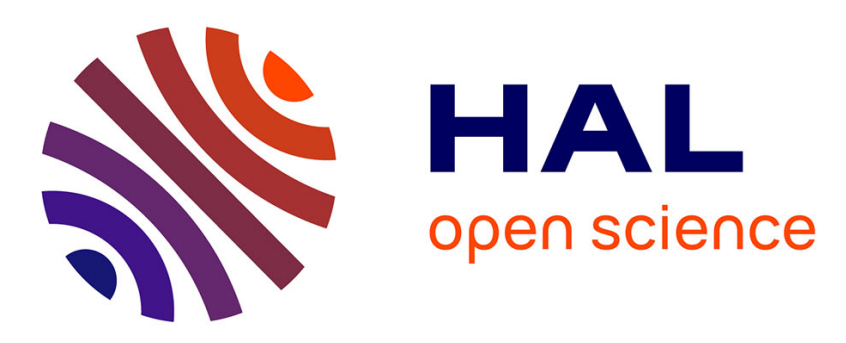

\title{
Formation of silicon nanocrystals by thermal annealing of low-pressure chemical-vapor deposited amorphous $\operatorname{SiNx}(x=0.16)$ thin films
}

Hakim Haoues, Hachemi Bouridah, Mahmoud Riad Beghoul, Farida Mansour, Riad Remmouche, Pierre Temple-Boyer

\section{To cite this version:}

Hakim Haoues, Hachemi Bouridah, Mahmoud Riad Beghoul, Farida Mansour, Riad Remmouche, et al.. Formation of silicon nanocrystals by thermal annealing of low-pressure chemical-vapor deposited amorphous SiNx $(\mathrm{x}=0.16)$ thin films. Materials Science in Semiconductor Processing, 2013, 16 (6), pp.1849-1852. 10.1016/j.mssp.2013.07.019 . hal-01508074

\section{HAL Id: hal-01508074 \\ https://hal.science/hal-01508074}

Submitted on 13 Apr 2017

HAL is a multi-disciplinary open access archive for the deposit and dissemination of scientific research documents, whether they are published or not. The documents may come from teaching and research institutions in France or abroad, or from public or private research centers.
L'archive ouverte pluridisciplinaire HAL, est destinée au dépôt et à la diffusion de documents scientifiques de niveau recherche, publiés ou non, émanant des établissements d'enseignement et de recherche français ou étrangers, des laboratoires publics ou privés. 
Formation of silicon nanocrystals by thermal annealing of low-pressure chemical-vapor deposited amorphous $\operatorname{SiN}_{x}(x=0.16)$ thin films

Hakim Haoues *.1, Hachemi Bouridah ${ }^{* *}$, Mahmoud Riad Beghoul ${ }^{1}$, Farida Mansour ${ }^{2}$, Riad Remmouche ${ }^{1}$, Pierre Temple-Boyer ${ }^{3.4}$

${ }^{1}$ Département d'Electronique, Université de Jijel, B.P. 98, OuledAissa, Jijel 18000, Algeria

${ }^{2}$ Département d'Electronique, Université Mentouri, Route d'Ain El-Bey, Constantine 25000,

\author{
Algeria \\ ${ }^{3}$ CNRS, LAAS, 7 av. du colonel Roche, F-31077 Toulouse, France \\ ${ }^{4}$ UPS, INSA, INP, ISAE, LAAS, Université de Toulouse, F-31077 Toulouse, France \\ * Corresponding author: e-mail h.haoues2@gmail.com, Phone: +213 661183167 \\ **e-mail hbouridah@yahoo.fr
}

Keywords: Silicon nanocrystals, Crystallite size, Crystallinity, Photoluminescence. 


\begin{abstract}
Silicon nanocrystals have been produced by thermal annealing of $\mathrm{SiN}_{\mathrm{x}}$ thin film obtained by low pressure chemical vapor deposition using a mixture between disilane and ammonia. Morphological, structural, and photoluminescence properties of the thin film were investigated using X-ray diffraction, scanning electron microscopy, Raman spectroscopy and photoluminescence spectroscopy. The results revealed a high crystallinity of film with a crystalline volume fraction exceeded $70 \%$, and a dominance of silicon nanocrystallites having the sizes within the range $2.5-5 \mathrm{~nm}$ and density $\sim 1.98 .10^{12} / \mathrm{cm}^{2}$. The PL peaks consist of nanocrystalline silicon and amorphous silicon. The luminescence from the silicon nanocrystals was dominant.
\end{abstract}

\title{
1. Introduction
}

A great deal of interest has been devoted recently to silicon nanocrystals ( $\mathrm{Si}-\mathrm{NCs}$ ) due to the potentiality of Si-NCs in nanoelectronic applications such as channel layer of thin films transistor leading to a great enhancement in carrier mobility [1], and in optoelectronic applications because $\mathrm{Si}-\mathrm{NCs}$ is expected to exhibit a quantum size effect [2-4]. The origin of photoluminescence (PL) was described by the quantum confinement model and by the surface model. Fabrication of Si-NCs films, having a highly efficient quantum-size effect, requires both a reduction in the grain size, and an enhancement in the crystallites density.

For the proper application of photoluminescent $\mathrm{Si}-\mathrm{NCs}$ in devices, the silicon crystallites must be embedded in a dielectric matrix. Many researchers have investigated the light 
emission from silicon nanostructures embedded in silicon oxide films due to its easy processing, and its full compatibility with complementary metal oxide semiconductor (CMOS) technology [5,6]. However, a too large band gap of the silicon oxide handicaps the injection of the carriers that reduces the efficiency and reliability of the devices. $\mathrm{SiN}_{\mathrm{x}}$ is a preferred dielectric matrix because of its low barrier high charge trapping capacity and high carrier mobility. Several chemical vapor deposition (CVD) techniques were used for Si-NCs production in $\mathrm{SiN}_{\mathrm{x}}$ with various compositions [7-9]. Depending on the preparation parameters, the PL was attributed either to the quantum confinement of Si-NCs or to radiative defects [1013]. The type of defects strongly depends on the deposition parameters such as stoichiometry and post deposition treatments. Indeed, the presence of nitrogen with high proportions favors the appearance of radiative defects.

In order to enhance the quantum confinement effect, we propose a method allowing the formation of $\mathrm{Si}-\mathrm{NCs}$ in an intermediate structure between amorphous silicon and silicon nitride. In the quest to develop such a material, we anneal at high temperature amorphous $\mathrm{SiN}_{0.16}$ thin film obtained by low pressure chemical vapor deposition (LPCVD) using a mixture between disilane $\left(\mathrm{Si}_{2} \mathrm{H}_{6}\right)$ and ammonia $\left(\mathrm{NH}_{3}\right)$. LPCVD which is a process compatible with CMOS technology offers several advantages such as the reduction of both the rate of the reaction permitting greater control over film thickness, and the thickness variations. It also improves the film's purity (low defects number) and internal structure. The simplicity of the process permits the processing of large wafer batch sizes. 
The crystallization of amorphous LPCVD silicon thin film by using $\mathrm{Si}_{2} \mathrm{H}_{6}$ gaseous that allows deposits at very low temperatures $\left(420-520 \quad{ }^{\circ} \mathrm{C}\right)$; i.e. lower than the silicon crystallization temperature $\left(\approx 580{ }^{\circ} \mathrm{C}\right)$ with a high deposition rates, allowing to separate the deposition and the crystallization phenomena, provides a polycrystalline structure characterized by a high crystalline volume fraction $\left(\mathrm{X}_{\mathrm{c}}\right)$ and micrometric grains sizes [14]. $\mathrm{Si}_{2} \mathrm{H}_{6}$ and $\mathrm{NH}_{3}$ gas mixture offers the possibility to realize different types of materials between the silicon nitride and amorphous silicon, and hence it is possible to introduce low nitrogen content necessary to obtain high silicon crystallites concentration with smaller sizes. Indeed, the excess of silicon in films allows high silicon crystallites concentration after heat treatment while the nitrogen atoms increase the disorder in the silicon network during the film deposit phase [15] in one hand and suppress the crystallites growth during the thermal annealing process, in the other hand. We combine in our crystallization process a high temperature annealing $\left(1100{ }^{\circ} \mathrm{C}\right)$ to activate the nucleation phenomena with a short annealing duration $(1 \mathrm{~min})$ in order to avoid an eventual enhancement in the silicon crystallites sizes.

\section{Experimental}

The deposit of amorphous $\operatorname{SiN}_{\mathrm{x}}(\mathrm{x}=\mathrm{N} / \mathrm{Si})$ thin film (thickness around $200 \mathrm{~nm}$ ) was carried out in a conventional hot-wall, horizontal, LPCVD furnace by using $\mathrm{Si}_{2} \mathrm{H}_{6}$ and $\mathrm{NH}_{3}$ gaseous mixture, on $10 \mathrm{~cm}$, (111), oxidized (about $120 \mathrm{~nm}$ of oxide) silicon wafers. The deposition pressure $\mathrm{P}$ and the temperature deposition $\mathrm{T}$ were respectively fixed to 200 mTorr and $465^{\circ} \mathrm{C}$. Ellipsometry and energy dispersive X-ray spectrometry confirmed the 
composition of the film to be $\mathrm{SiN}_{0.16}$. The film thickness was measured by ellepsometry and checked by profilometry. Thermal annealing process was performed at $1100{ }^{\circ} \mathrm{C}$ during $1 \mathrm{~min}$ into a conventional furnace under nitrogen $\left(\mathrm{N}_{2}\right)$ ambient.

The X-ray diffraction (XRD) study of film was performed on a D8 Advance Bruker AXS diffractometer with $\mathrm{CuK} \alpha$ radiation equipped with a curved graphite monochromator. According to both the thicknesses of $\operatorname{SiN}_{\mathrm{x}}$ thin film ( $200 \mathrm{~nm}$ ) and underlying oxide layer $(120 \mathrm{~nm})$ the incidence ray was oriented with an angle of $0.3^{\circ}$, so that the Bragg condition can not be satisfied for the substrate. The data were collected in the $2 \theta^{\circ}$ range of $25-80^{\circ}$ with a step size of $0.03^{\circ}$ and a count time of 2 s per step. Scanning electron microscopy (SEM) analysis of the sample was done using Philips model XL 30. The grain size distribution (GSD) and the crystalline volume fraction $\mathrm{X}_{\mathrm{c}}$ were determined via imageprocessing techniques. Raman spectroscopy analysis has been carried out using a LabRAM Jobin -Yvon spectrometer. The excitation wave-length was the $488 \mathrm{~nm}$ line of an Argon laser in the backscattering configuration. The laser spot on the sample was kept at a power density low enough to avoid temperature effects (about $6 \mathrm{~mW}$ over the sample). The PL was measured using a laser excitation source wavelength of $355 \mathrm{~nm}$. The laser beam has a power density of $3.27 \mathrm{~mW}$ and a spot diameter of few $\mathrm{mm}$ and a resolution of $6.8 \mathrm{~nm}$.

\section{Results and discussion}

Figure 1 shows the XRD spectrum of the $\mathrm{SiN}_{0.16}$ film. The film deposited in the amorphous state crystallizes in the (111) crystalline direction. Based on Scherer formula, the 
average crystallite size of nanocrystalline silicon is calculated from the full width at halfmaximum (FWHM) of the (111) diffraction peak as $7 \mathrm{~nm}$. Noticing, that XRD spectrum represents the deconvolution of the diffraction of all silicon crystallites with different sizes. Thus, this size value represents an average size of all silicon crystallites.

Figure 1

To have a direct view of the silicon crystallites, SEM measurements were performed. Figures 2 and 3 depict, respectively, the SEM image and GSD of $\mathrm{SiN}_{0.16}$ film annealed at $1100{ }^{\circ} \mathrm{C}$ during $1 \mathrm{~min}$.

Figure 2

Figure 3

The SEM image shows clearly the crystallization of film characterized by the existence of nanocrystalline silicon (bright regions) in contrast to the amorphous matrix (dark regions in SEM image). As shown in the inset, each cluster consists of subgrains and amorphous phase between the grains.

The grain size distribution and the crystalline fraction are determined by image analysis using the wavelet edge detection method [16]. The equivalent diameter $\mathrm{g}$ of a grain is obtained using the following expression [17]:

$g=2 \sqrt{A / \pi}$ 
Where $\mathrm{A}$ is the surface of a grain.

The wavelet edge detection method can be used for drawing the contours of grains before determining their size distribution. Thus, the grain size distribution is determined in two steps. The first one concerns the extraction of the grains' outline. The second concerns the calculation of the grains' size in order to determine their distribution according to:

- determining the number of pixels in the image scale;

- determining the number of pixels in each grain;

- calculation of the grains number in the image;

- calculation of the grains diameters using the expression (1) and thus the maximum size and average grain size.

The GSD is then normalized by dividing the corresponding value for each size by the total number of grains.

The crystalline fraction $X_{c}$ is calculated using the following expression [18]:

$$
X_{c}=\left(\frac{S_{\text {crystallites }}}{S_{\text {crystallites }}+S_{\text {amorphous }}}\right)^{3 / 2}
$$

Where $S_{\text {amorphous }}$ and $S_{\text {crystalites }}$, represent the total crystalline area and the total amorphous area, respectively.

We calculate an average silicon crystallites size of $6.3 \mathrm{~nm}$ in good agreement with the size provided by XRD and a crystalline volume fraction $\mathrm{X}_{\mathrm{c}}=80 \%$. This large value of $\mathrm{X}_{\mathrm{c}}$ 
implies the presence of a high density of silicon crystallites. Indeed, through the analysis of GSD, it may be noted that $71 \%$ of nanocrystallites have sizes within the range $2.5-8 \mathrm{~nm}$, among this proportion, $90 \%$ of the crystallites have sizes within the range $2.5-5 \mathrm{~nm}$ and density $\sim 1.98 .10^{12} / \mathrm{cm}^{2}$. The lowest value of the crystallites proportion $(0.26 \%)$ is attributed to crystallites having sizes within the range $30-40 \mathrm{~nm}$.

Raman spectroscopy is a sensitive tool for studying Si-NCs material because it gives direct structural evidence quantitatively related to the nanocrystalline and amorphous component in the material. The formation of $\mathrm{Si}-\mathrm{NCs}$ in the $\mathrm{SiN}_{0.16}$ film after $1100^{\circ} \mathrm{C}$ annealing is also confirmed by Raman spectrum as shown in figure 4. The Gaussian deconvolution of the spectrum shows the presence of two peaks, a peak around $480 \mathrm{~cm}^{-1}$ which indicates the presence of amorphous silicon $[19,20]$ and another at $514 \mathrm{~cm}^{-1}$ originating from nanocrystalline phase in the film [19]. Note that the peak characteristic of $\mathrm{Si}-\mathrm{NCs}$ is more intense than that of amorphous silicon showing a formation of a significant portion of nanocrystalline silicon in the annealed thin film. Quantitative estimation of $X_{c}$ can be performed via the two Gaussian components by using the following formula [21]:

$$
X_{c}=I_{c} /\left(I_{c}+\eta * I_{a}\right)
$$

Where $I_{c}$ is the Gaussian integration intensity related to crystalline composition, Ia is the integration intensity related to amorphous composition in Raman spectrum and $\eta=0.88$ represents the fitted factor. The $\mathrm{X}_{\mathrm{c}}$ extracted from Raman spectra is equal to $73 \%$. The slight difference of this value, comparing it with the data provided by SEM analysis (a difference of $7 \%$ ) can be attributed to the specificity of measurement and calculation of each method. 
Figure 4

Figure 5

The PL spectrum of $\mathrm{SiN}_{0.16}$ film as a function of photon wavelength is plotted in figure 5. This spectrum shows an emission band between $500 \mathrm{~nm}$ and $740 \mathrm{~nm}$ corresponding to luminescence energies of $2.5 \mathrm{eV}$ and $1.68 \mathrm{eV}$ respectively, with a maximum at $578 \mathrm{~nm}$ $(2.13 \mathrm{eV})$. Gaussian deconvolution of the PL spectrum clearly identifies three peaks of different wavelength, namely, a peak at $617 \mathrm{~nm}(2 \mathrm{eV})$ related to the quantum dots in the amorphous silicon [22], a peak characterized by the highest intensity at a wavelength of $578 \mathrm{~nm}(2.13 \mathrm{eV})$ and a peak at $673 \mathrm{~nm}(1.84 \mathrm{eV})$. The latter two peaks are associated with Si-NCs $[23,24]$.

By using the expression proposed by Kim et al [25], it is possible to access to the size of silicon nanocrystallites knowing their luminescence energies by the following formula:

$$
E_{C}=1.13+13.9 / d^{2}
$$

Where $\mathrm{d}$ is a diameter of nanocrystals.

We calculate a nanocrystallites size of $3.72 \mathrm{~nm}$ corresponding to the PL energy $\mathrm{E}_{\mathrm{c}}=2.13 \mathrm{eV}$ and a nanocrystallites size of $4.42 \mathrm{~nm}$ corresponding to $\mathrm{E}_{\mathrm{c}}=1.84 \mathrm{eV}$. Both sizes are in the range of crystallites having the largest proportion as it has been provided by the SEM data. The light emission originating from quantum confinement effect, can be attributed 
to the high density of Si-NCs having the lowest sizes in one hand, and to high crystalline volume fraction level obtained after high thermal annealing, in the other hand [26].

Several of works have been published on photoluminescence from nanostructured silicon, which includes crystalline or amorphous silicon quantum dots embedded in amorphous silicon matrix or $\mathrm{SiN}_{\mathrm{x}}$ dielectric matrix synthesized by various chemical and physical vapor deposition routes $[10-13,26,27]$. The investigations have mainly concerned the formation of $\mathrm{Si}-\mathrm{NCs}$ by using silane $\left(\mathrm{SiH}_{4}\right)$ as precursor gas. In such structures, the crystallinity in terms of volume crystalline fraction and crystallites size, and the PL origin are a compromise between a large process parameters number, which makes difficult a rigorous comparison between the different methods. The originality of this work is that the proposed method (LPCVD deposit process, $\mathrm{Si}_{2} \mathrm{H}_{6}$ precursor gas, high thermal annealing), allowed us the production of a high density of luminescent $\mathrm{Si}-\mathrm{NCs}$ in $\mathrm{SiN}_{\mathrm{x}}$ matrix.

\section{Conclusion}

Silicon nanocrystallites formation in annealed amorphous LPCVD $\mathrm{SiN}_{0.16}$ thin film has been investigated. The results revealed the production of nanocrystals film characterized by a large crystalline volume fraction in which the highest silicon crystallites proportion is attributed to the crystallites having the lowest sizes. PL spectrum has been separated into three Gaussian peaks. Two peaks were attributed to silicon nanocrystals and one peak to amorphous silicon. The luminescence from silicon nanocrystals was dominant. The high crystallinity of the obtained silicon nanocrystals film offers to the material large applications in nanoelectonic and optoelectronic fields. 


\section{References}

[1] I.Y.Y. Bu, A.J. Flewitt, W.I. Milne, High mobility, bottom gate, nanocrystalline silicon thin film transistors incorporating a nitrogenated incubation layer, Curr. Appl. Phys. 11 (2011) 171-175.

[2] N. Dandosso, G. Das, S. Larcheri, G. Mariotto, G. Dalba, L. Pavesi, A. Irrera, F. Priolo, F. Lacona, F. Rocca, Silicon nanocrystal formation in annealed silicon-rich silicon oxide films prepared by plasma enhanced chemical vapor deposition, J. Appl. Phys. 101 (2007) 113510.

[3] A.M. Funde, N.A. Bakr, D.K. Kamble, R.R. Hawal-dar, D.P. Amalnerkar, S.R. Jadkar, Influence of hydrogen dilution on structural, electrical and optical properties of hydrogenated nanocrystalline silicon $(\mathrm{nc}-\mathrm{Si}: \mathrm{H})$ thin films prepared by plasma enhanced chemical vapour deposition (PE-CVD), Sol. Energ. Mat. Sol. C. 92 (2008) 1217-1223.

[4] S. Kohli, J.A. Theil, P.C. Dippo, K.M. Jones, M.M. Al-Jassim, R.K. Ahrenkiel, C.D.

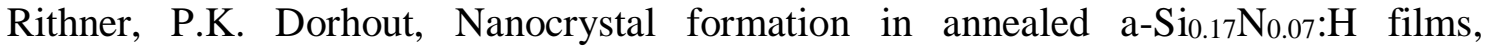
Nanotechnology 15 (2004) 1831-1836.

[5] C.C. Chen, Y. H. Lin, M. H. Shih, G. R. Lin, H. C. Kuo, Light Enhancement of SiliconNanocrystal-Embedded $\mathrm{SiO}_{x}$ Film on Silicon-on-Insulator Substrate, Jpn. J. Appl. Phys. 50 (2011) 04DJ09.

[6] D. Comedi, O.H.Y. Zalloum, E.A. Irving, J. Wojcik, T. Roschuk, M.J. Flynn, P. Mascher, X-ray-diffraction study of crystalline Si nanocluster formation in annealed silicon-rich silicon oxides, J. Appl. Phys. 99 (2006) 023518.

[7] L.D. Negro, J.H. Yi, L.C. Kimerling, S. Hamel, A. Williamson, A.G. Galli, Light emission from Si-rich nitride nanostructures, Appl. Phys. Lett. 88 (2006)183103.

[8] M. Dai, K. Chen, X. Huang, L. Wu, L. Zhang, F. Qiao, W. Li, K. Chen, Formation and charging effect of $\mathrm{Si}$ nanocrystals in $\mathrm{a}-\mathrm{SiN}_{\mathrm{x}} / \mathrm{a}-\mathrm{Si} / \mathrm{a}-\mathrm{SiN}_{\mathrm{x}}$ structures, J. Appl. Phys. 95 (2004) 640-645.

[9] L. Wang, X. Wang, X. Huang, Z. Li, Z. Ma, L. Zhang, Y. Bao, J. Shi, W. Li, X. Huang, Interface confinement and local structure in $\mathrm{nc}-\mathrm{Si} / \mathrm{a}-\mathrm{SiN} \mathrm{X}$ multilayer, J. Phys. Condens. Matter 13 (2001) 9857-9865.

[10] B. Sain, D. Das, Tunable photoluminescence from nc-Si/a-SiNx:H quantum dot thin films prepared by ICP-CVD, Phys. Chem. Chem. Phys. 15 (2013) 3881-3888.

[11] F. Delachat, M. Carrada, G. Ferblantier, J.J. Grob, A. Slaoui, Properties of silicon nanoparticles embedded in $\mathrm{SiN}_{\mathrm{x}}$ deposited by microwave-PECVD, Nanotechnology 20 (2009) 415608.

[12] M. Wang, D. Li, Z. Yuan, D. Yang, D. Que , Photoluminescence of Si-rich silicon nitride: Defect-related states and silicon nanoclusters, Appl. Phys. Lett. 90 (2007) 131903.

[13] B.H. Kim, C.H. Cho, T.W. Kim, N. M. Park, G. Y. Sung, S. J. Park, Photoluminescence of silicon quantum dots in silicon nitride grown by $\mathrm{NH}_{3}$ and $\mathrm{SiH}_{4}$, Appl. Phys. Lett. 86 (2005) 091908.

[14] P. Temple-Boyer, B. Rousset, E. Scheid, Properties of silicon thin films obtained by low-pressure chemical vapour deposition, Thin Solid Films 518 (2010) 6897- 6903.

[15] H. Bouridah, F. Mansour, M.R. Beghoul, R. Mahamdi, P. Temple-Boyer, Properties of non-stoichiometric nitrogen doped LPCVD silicon thin films, Crys. Res. Technol. 45 (2010) 119-123.

[16] Z. Zhang, S. Ma, H. Liu, Y. Gong, An edge detection approach based on directional wavelet transform, Comput. Math. Appl. 57 (2009) 1265-1271. 
[17] Allen LH, Mayer JW, Tu KN, Feldman LC, Kinetic study of Si recrystallization in the reaction between Au and polycrystalline-Si films, Phys. Rev. B 41 (1990) 8203-8212.

[18] H. Bouridah, F. Bouaziz, F. Mansour, R. Mahamdi, P.Temple-Boyer, Study of grains size distribution and electrical activity of heavily boron doped polysilicon thin films, Mat. Sci. Semicon. Proc. 14 (2011) 261-265.

[19] V. A. Volodin, M. D. Efremov, V. A. Gritsenko, S. A. Kochubei, Raman study of silicon nanocrystals formed in SiNx films by excimer laser or thermal annealing, Appl. Phys. Lett. 73 (1998)1212.

[20] K. Panchal, C.S. Solanki, Fabrication of silicon quantum dots in SiNx multilayer using hot-wire CVD, J. Cryst. Growth. 311 (2009) 2659-2663.

[21] W. Wenshenga, W. Tianmin, Z. Chunxi, L. Guohua, H. Hexiang, D. Kun, referred growth of nanocrystalline silicon in boron-doped nc-Si:H Films, Vacuum 74 (2004) 6975 .

[22] N.M. Park, C.J. Choi, T.Y. Seong, S.J. Park, Quantum Confinement in Amorphous Silicon Quantum Dots Embedded in Silicon Nitride, Phys. Rev. Lett. 86 (2001) 1355 1357.

[23] K.M. Lee, T.H. Kim, J.D. Hwang, S. Jang, K. Jeong, M. Han, S. Won, J. Sok, K. Parka, W.S. Honga, Size control of silicon nanocrystals in silicon nitride film deposited by catalytic chemical vapor deposition at a low temperature $\left(\leq 200{ }^{\circ} \mathrm{C}\right)$, Scripta. Mater. 60 (2009) 703-705.

[24] C.T. Lin, C. Liu, G.R. Lin, Luminescen t-w avelength tailoring silicon-rich silicon nitride LED, Chin. Opt. Lett. 7 (2009) 277-279.

[25] T.W. Kim, C.H. Cho, B.H. Kim, S.J. Park, Quantum confinement effect in crystalline silicon quantum dots in silicon nitride grown using $\mathrm{SiH}_{4}$ and $\mathrm{NH}_{3}$, Appl. Phys. Lett. 88 (2006) 123102.

[26] A.M. Ali, T. Inokuma, S. Hasegawa, Structural and photo-luminescence properties of nanocrystalline silicon films deposited at low temperature by plasma-enhanced chemical vapor deposition, Appl. Surf. Sci. 253 (2006) 1198-1204.

[27] S.K. Kim,C.H. Cho,B.H.Kim,S.J. Park,J. W. Lee, Electrical and optical characteristics of silicon nanocrystal solar cells, Appl. Phys. Lett. 95 (2009) 143120. 


\section{Figure Captions}

Figure 1: $\mathrm{XRD}$ spectrum of $\mathrm{SiN}_{0.16}$ film annealed at $1100{ }^{\circ} \mathrm{C}$ for $1 \mathrm{~min}$.

Figure 2: SEM image of $\mathrm{SiN}_{0.16}$ after heat treatment at $1100{ }^{\circ} \mathrm{C}$ for $1 \mathrm{~min}$.

Figure 3: Histogram of grain size distribution of $\mathrm{SiN}_{0.16}$ film annealed at $1100{ }^{\circ} \mathrm{C}$ for $1 \mathrm{~min}$.

Figure 4: Deconvoluted Raman spectrum of $\mathrm{SiN}_{0.16}$ film annealed at $1100{ }^{\circ} \mathrm{C}$ for $1 \mathrm{~min}$.

Figure 5: PL spectrum of $\mathrm{SiN}_{0.16}$ film annealed at $1100{ }^{\circ} \mathrm{C}$ for $1 \mathrm{~min}$ with deconvoluting Gaussian peaks. 


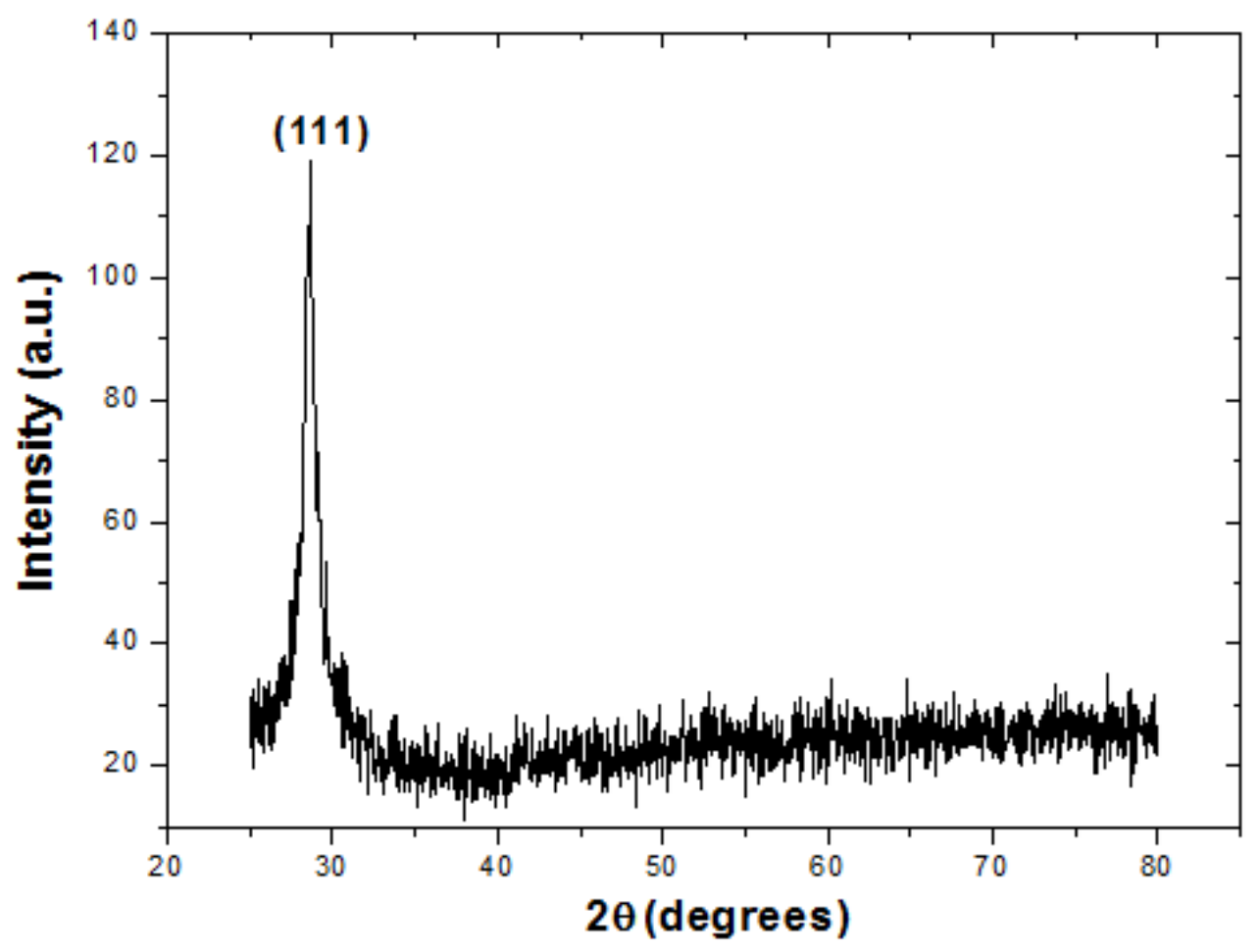

Figure 1 


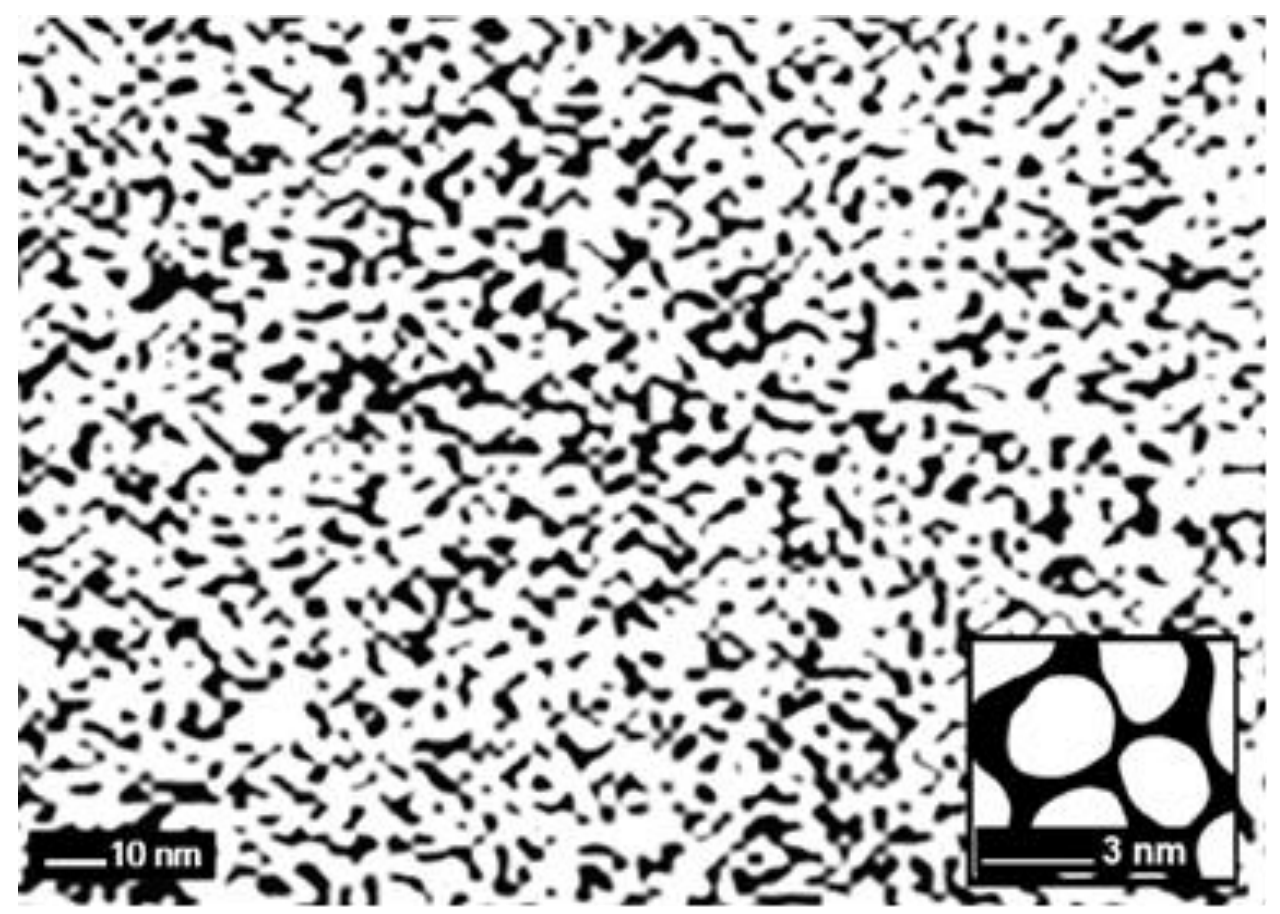

Figure 2 


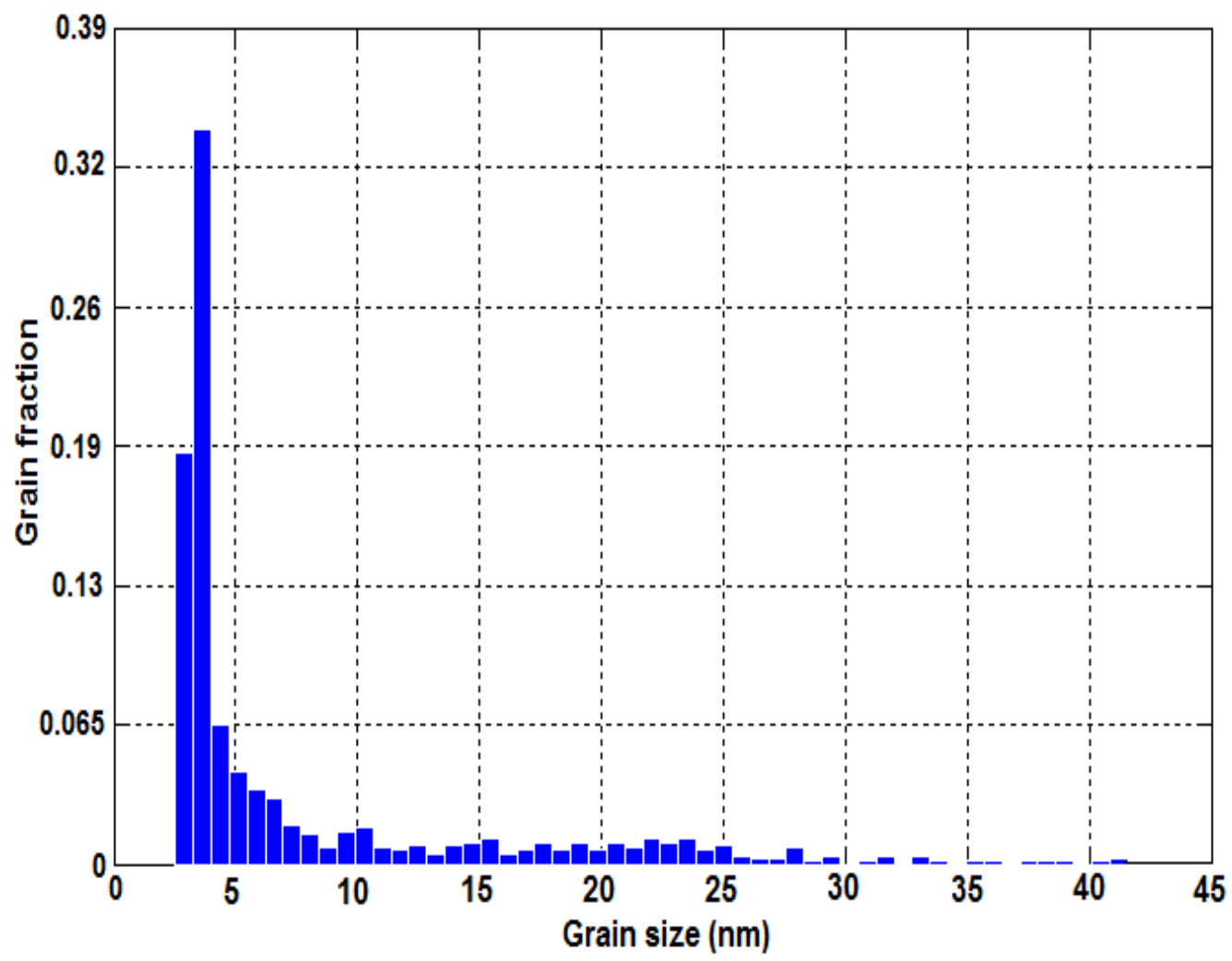

Figure 3 


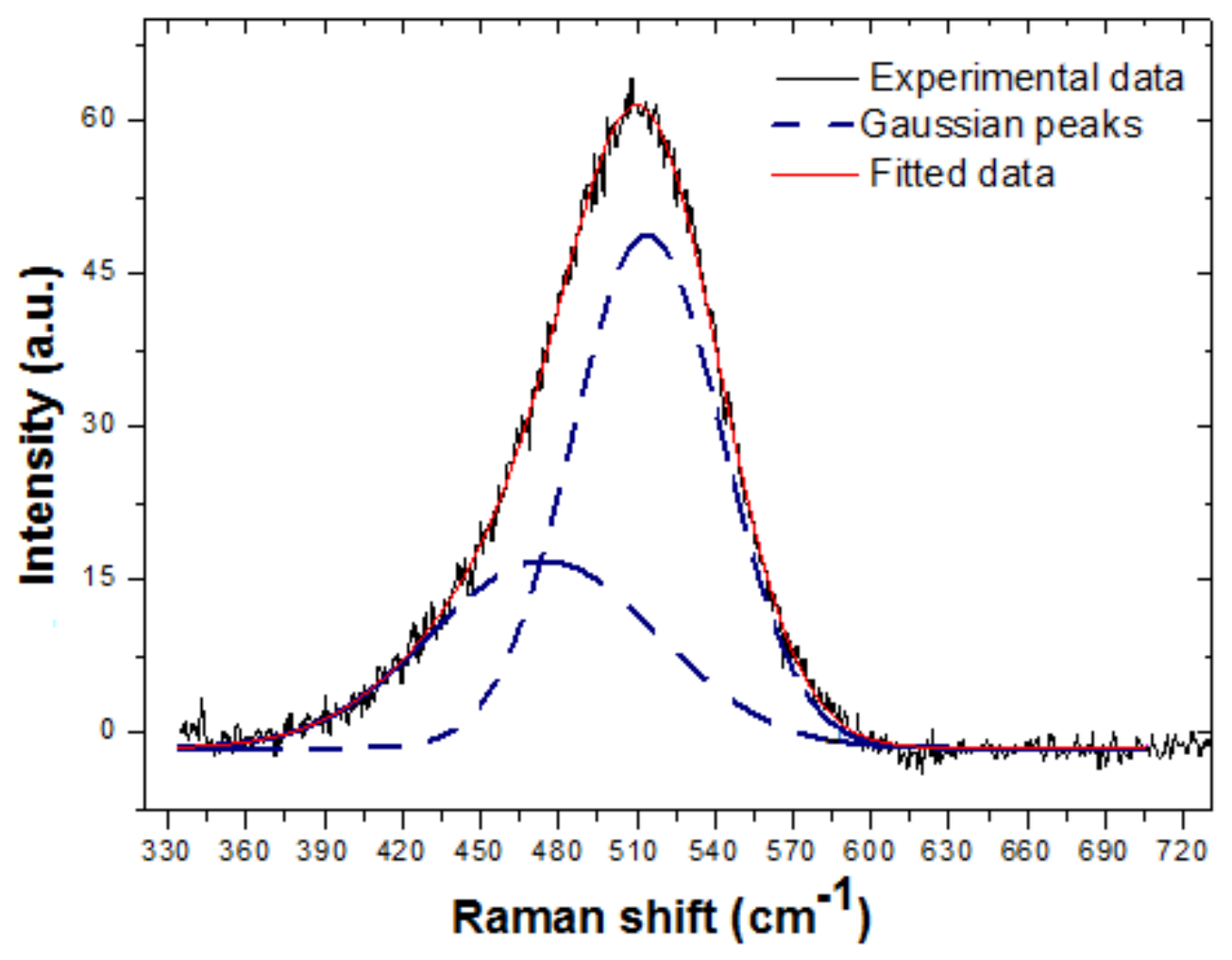

Figure 4 


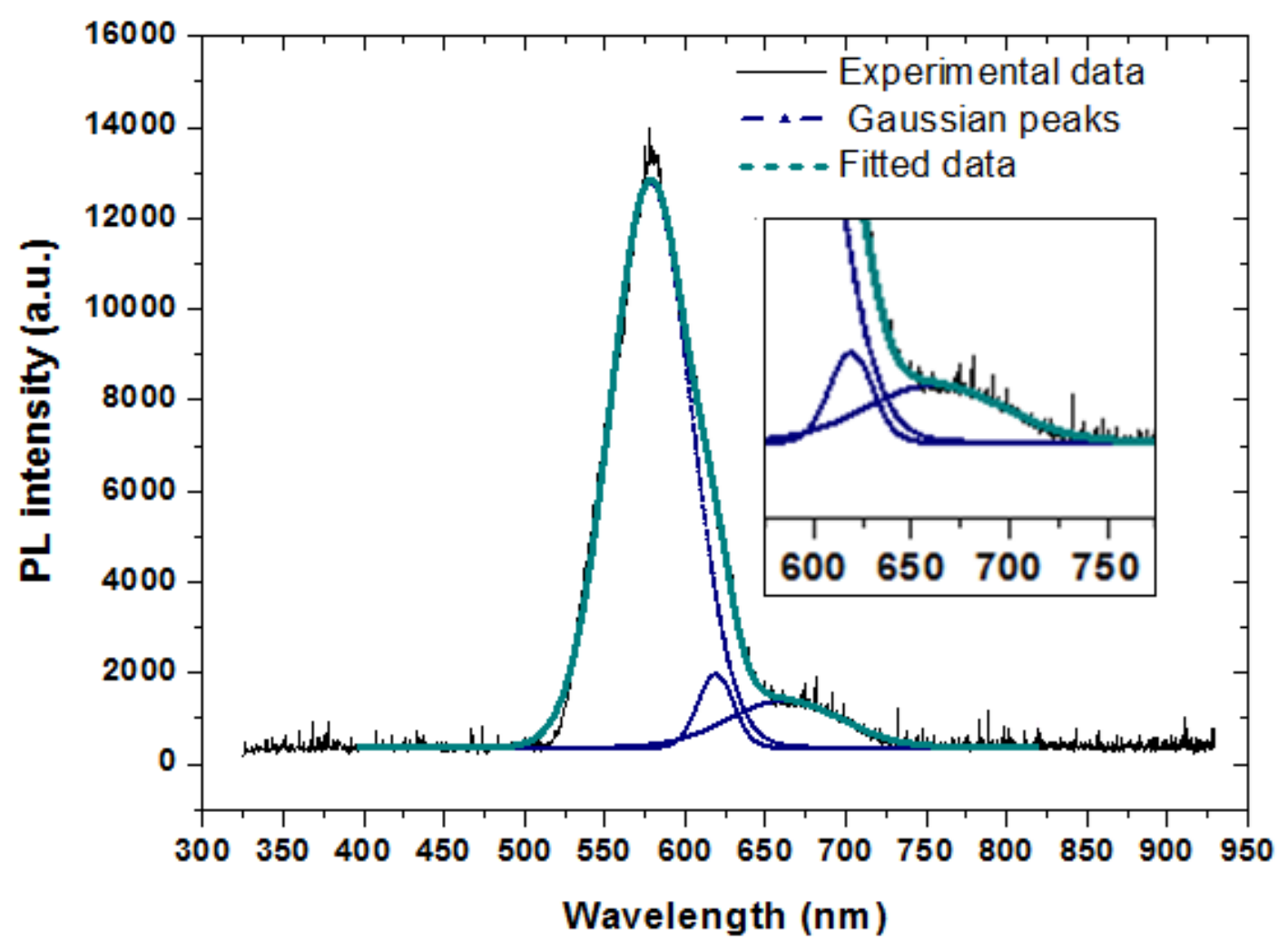

Figure 5 